Res Publica. Revista de Historia de las Ideas Políticas

ISSN-e: 1989-6115

http://dx.doi.org/10.5209/rpub.66186

\title{
Verdad, vida y texto en el reflejo repetido de Friederike Brion: una relectura de los libros X y XI de Poesía y verdad de J.W. Goethe
}

\author{
Kilian Lavernia*
}

Recibido: 6 de febrero de 2019 / Aceptado: 4 de octubre de 2019

Resumen. El artículo propone una relectura de los libros X y XI de Poesía y verdad (1813), de Johann Wolfgang Goethe, con el fin de dignificar la figura femenina, aparentemente menor, de Friederike Brion. En primer lugar, nos acercaremos al relato goetheano de la mano de Jacques Lacan, a partir de cuyas indicaciones sobre el mito individual del neurótico iremos introduciendo el episodio amoroso construido por el poeta. A continuación, ampliaremos la mirada con una reflexión tardía de Goethe sobre dicho episodio, tal como plasmó en su breve ensayo "Reflejos repetidos", de 1823. Gracias al juego de espejos generados en y por el texto autobiográfico, la presencia de la persona amada sólo emerge, para el viejo escritor, asumiendo una dimensión entóptica de la vida, de ahí que en Friederike identifique un estatuto simbólico que someteremos a consideración. Por último, desde cierto trabajo intertextual, mostraremos algunos campos proyectivos en Poesía y verdad desde los que la dignidad hermenéutica de Friederike podría ser revaluada.

Palabras clave: Goethe; Friederike Brion; Poesía y verdad; autobiografía.

\section{[en] Truth, Life and Text in Friederike Brion's Repeated Reflections: Rereading Books X and XI of Poetry and Truth by J.W. Goethe}

\begin{abstract}
The article offers a rereading of Books X and XI of Johann Wolfgang Goethe's Poetry and Truth (1813), in order to dignify the apparently minor female figure of Friederike Brion. First, we will approach Goethe's construction through the eyes of Jacques Lacan, whose remarks on the individual myth of the neurotic will serve as an introduction to the Goethean love affair. Second, we'll expand the scope by analyzing Goethe's late text of 1823 , "Repeated reflections", where the old poet reflected upon that affair. Thanks to the mirror game generated in and by the autobiographical text, the presence of the once loved only emerges for the old writer by assuming an entoptical dimension of life, in which the figure of Friederike gains a symbolic status we will take into consideration. From a certain intertextual perspective we will -finally- show some passages of Poetry and Truth where the hermeneutical dignity of Friederike could be reevaluated.
\end{abstract}

Keywords: Goethe; Friederike Brion; Poetry and Truth; Autobiography.

Sumario: 0. Goethe y las mujeres: a modo de introducción. 1.Lacan en Estrasburgo. 2. El deseo reflejado, o sobre la dimensión entóptica. 3. ¿Quién es Friederike? Algunos hilos de los que tirar. 4. Epílogo a modo de invitación.

Cómo citar: Lavernia, K. (2019). Verdad, vida y texto en el reflejo repetido de Friederike Brion: una relectura de los libros X y XI de Poesía y verdad de J.W. Goethe, en Res Publica 22.3, 727-743.

UNED.

klavernia@fsof.uned.es 


\section{Goethe y las mujeres: a modo de introducción.}

Cuando nos acercamos al entramado de las figuras de lo femenino en la obra autobiográfica de Johann Wolfgang Goethe, una de las sensaciones que quizá emerge con mayor nitidez es la del vértigo inherente a toda cuestión literaria que, aun sabiendo que trasciende el plano estético para sedimentarse como momento configurador de cultura, nos obliga al mismo tiempo a tomar cautelas críticas. Frente al estilizado mito construido por el poeta debemos estar siempre prevenidos. Cierto, en la meditada reconstrucción de su vida amorosa se juega el relato de una autosuperación constante donde el eros goetheano parece ejercitarse una y otra vez en el arte fáustico de la Entsagung. No por casualidad el aprendizaje de esa renuncia en torno al momento amatorio siempre tuvo, para el viejo poeta, el rango de un arcano de la condición humana, como una clave existencial para la salud espiritual del sujeto moderno.

Al mismo tiempo, sin embargo, el gesto poético hacia aquellas mujeres que amó y lo amaron a él -desde Kätchen Schönkopf hasta Charlotte von Stein, desde Lili Schönemann hasta Ulrike von Levetzow, pasando por Friederike Brion, que centrará nuestras siguientes reflexiones- está cargado de la ambivalencia propia de toda elevación amatoria que, al tiempo que es glorificada en sus obras, nace de un momento real de sufrimiento y posterior abandono. Con ello se alcanza casi siempre, como contrapartida, un desarme emocional de sus protagonistas femeninas y una descontextualización en favor del anhelado símbolo, de su plasmación, verosimilitud y efectividad en el medium de una poderosa literatura autobiográfica. De sobra sabemos que el escritor alemán tendió siempre a eludir o mitigar la culpa y a procurar un sentido simbólico a sus debilidades, huidas y deserciones, evitando sin embargo cualquier autojustificación de sus verdaderas intenciones a la manera obsesiva y autocomplaciente de un Rousseau. Ahora bien, en cuanto símbolo de una trascendencia personal, las figuras de lo femenino que enriquecen su proteica vida adquieren visibilidad a través de una escritura autobiográfica que atenaza muchas veces la posibilidad de que aquellas mujeres amadas aparezcan también como figuras activas, determinables y reconocibles en virtud de la realidad ficticia del texto. Frente a ese desiderátum de autoafirmación y desmitificación inmanente al texto, las no pocas figuras femeninas que acompañaron algunos tramos decisivos de la vida goetheana sólo surgen a través de la emocionalidad del autor, del vínculo especulativo y anecdótico del poeta que eleva a categoría, una y otra vez, su experiencia vital con las mujeres en el largo camino formativo de autosuperación. Como vemos, el precio que Goethe nos hace pagar para que lo accidental adquiera el rango de algo necesario y universal, es decir, para que la (auto)estilizada vivencia en temas amatorios se nos revele como poéticamente verdadera y agradable para deleite de su público es, cuando menos, digno de revisión.

Por de pronto, pues, la principal dificultad del paisaje figural femenino en la vida goetheana podría resumirse en los siguientes términos. A diferencia de la obra dramática o novelística, donde quizá parece más fácil refrendar la capacidad hermenéutica de la literatura universal, en la medida en que personajes clásicos como Lotte, Ifigenia, Margarita, Otilia o Mignon pueden terminar expresando fuerzas subjetivas que operan en cada individuo, los personajes femeninos que pueblan la obra autobiográfica están atenazados por un eros impulsado por un deseo tiránico de comunicarse a sí mismo y a sus lectores. Por si fuera poco, esta concepción de autobiografía re- 
vela la dimensión casi donjuanesca con la que representó su relación con las mujeres antes aludidas, emplazándolas en lo demoníaco y anudando así su destino personal como víctima de la Weiblichkeit ${ }^{1}$.

Es cierto que desde la irrupción de los estudios culturales y de género en la Goetheforschung, las cotas de reflexividad literaria y de conciencia crítica que han podido conquistarse releyendo la obra goetheana desde la mirada renovada sobre lo femenino nos señalan estrategias y perspectivas de enorme valor. Algunos ejemplos bastarán para ilustrar esta idea, que de entrada sirve para poner en barbecho la tradición tópica de lo eternamente femenino ${ }^{2}$. Ni la deconstrucción de la iconografía, los símbolos y arquetipos femeninos diseminados por su ingente obra, empezando por el Fausto; ni la visualización de la dimensión social e individual del matrimonio o la maternidad en su novelística, desde el Werther hasta el Wilhelm Meister y Las afinidades electivas, y su reflejo semiótico y discursivo en los códigos morales imperantes; ni siquiera la crítica a la representación dramatúrgica de la identidad femenina desde cierta normatividad estética, como en Stella o Ifigenia; en definitiva, ninguno de estos abordajes sobre el texto goetheano hubiera surgido como tal sin la correspondiente reactualización interdisciplinar de los literary studies, a caballo entre la literatura comparada y la historia cultural, no menos que la crítica literaria feminista, el psicoanálisis y el ecocriticismo, por nombrar algunas de las corrientes involucradas en esta ganancia de complejidad.

En este sentido, que el estado de la cuestión someramente perfilado debe servir para continuar transitando con nuevos incentivos algunos aspectos de las figuraciones de lo femenino en la obra autobiográfica de Goethe, es algo que -entrando ya en materia- quisiera sugerir con una problematización de los libros X y XI de Poesía $y$ verdad (1813), que comprenden el relato de los años formativos en Estrasburgo, entre marzo de 1770 y agosto de $1771^{3}$. Me refiero, más específicamente, al lugar que ocupa la figura de Friederike Brion en el entramado de una ficcionalidad autobiográfica que, por su condición enigmática entre literatura y vida, supera la tradicional alternativa entre reflejar lo subjetivo u observar lo objetivo. Este episodio de la vida del poeta, que narra el idilio alsaciano mantenido con la joven hija de un pastor luterano en la vicaría rural de Sesenheim, me servirá para dignificar esta aparente figura menor, y ello desde dos vertientes.

Con razón Eva Parra ha llegado a hablar, a este respecto, de "una especie de vampirismo afectivo", cf. E Parra, "Las mujeres de Goethe: de Ifigenia a Martha Schwerdtlein", en L. A. Acosta, M. L. Esteve, I. Hernández y M. Raders (eds.), Encuentros con Goethe, Madrid, Trotta, 2001, pp. 369-388, aquí p. 373.

2 Las siguientes reflexiones sobre el estado de la cuestión se inspiran, por un lado, en tratamientos integrales de Goethe y lo femenino como los firmados por B. Bennet, Goethe as Woman. The Undoing of Literature, Detroit, Wayne State University Press, 2003; B. Dumiche, Weiblichkeit im Jugendwerk Goethes. Die Sprachwerdung der Frau als dichterische Herausforderung, Würzburg, Königshausen \& Neumann, 2002; Ch. Bürger, Goethes Eros, Frankfurt a.M., Insel Verlag, 2009; J. Brown, Goethe's Allegories of Identity, Philadelphia, University of Pennsilvania Press, 2014; o los plasmados en obras colectivas tan recomendables como Goethe's Ghosts: Reading and the Persistence of Literature, S. J. Richter y R. Block (eds.), Rochester (NY), Camden House, 2013. Por el otro, no es menos decisiva la relectura de obras goetheanas concretas, pues ejemplifican perspectivas metodológicas y abordajes temáticos de enorme utilidad para pensar el binomio de Goethe y los paisajes de lo femenino diseminados por su escritura. A título de simple ejemplo, baste con pensar en las refrescantes relecturas críticas del Werther en clave feminista, incidiendo en los temas del baile y la maternidad, firmadas, respectivamente, por L. Ruprecht, "Werthers Walzer: Tanz als kulturelle Kodierung von Liebe und Intimität", en Goethe-Jahrbuch 128, 2011, pp. 44-59, y L. Nosset, "Impossible Ideals: Reconciling Virginity and Maternity in Goethe's Werther", en Goethe Yearbook XXIII, 2016, pp. 77-93.

3 J. W. Goethe, Poesía y verdad, traducción de R. Sala Rose, Barcelona, Alba Editorial, 1999, pp. 409-517. 
1) Por un lado, en diálogo con Jacques Lacan y su interpretación de dicho episodio $^{4}$, reflexionaré sobre la potencialidad de una escritura y reescritura de sí que funciona, no como mera introspección retrospectiva sobre el objeto deseado llamado Friederike, sino como construcción simbólica de "espejos" o más bien "reflejos repetidos" (wiederholte Spiegelungen), tal como Goethe explicará en un texto de título homónimo recurriendo a la analogía de los llamados "fenómenos entópticos". De ahí la importancia que concederé, junto a los mentados libros de Poesía y verdad, a este brevísimo ensayo de 1823, publicado póstumamente por Eckermann y del que, hasta donde tengo conocimiento, no existe una versión en castellano ${ }^{5}$. Condicionado por la tarea de convertir su vida en obra de arte, tarea en la que el "yo" sólo se reconoce si se deja temporalizar en un proceso de superación continua de sí, la actitud existencial estética adoptada por el viejo Goethe en este juego de espejos nos mostrará que en el personaje llamado Friederike Brion se problematiza, entre otros aspectos, la derivada que emerge entre representación literaria y memoria, entre imagen y repetición. La reconfiguración del recuerdo amoroso revelará, entrelazando la dimensión activa y narrativa de ese "yo" en la batalla contra la propia existencia, algunas de las estructuras del tiempo literario que la escritura autobiográfica goetheana ensaya en su combate contra la transitoriedad del deseo. Ello revelará la defensa de un camino formativo, de un impulso de formación poética no ceñido solo a la vocación como profesión, sino también extendido al terreno del goce, y de un ethos, siempre irónico, apasionado por el amor. Como mecanismo especular de reconocimiento de sí mismo en la actividad y en sus frutos, la tardía reflexión goetheana sobre esta figura femenina posee un valor filosófico nada desdeñable, que merece reivindicarse más allá del habitual biografismo que la ha petrificado en el panteón atemporal de los objetos poéticos condenados a permanecer jóvenes y adorables, pasivos e instrumentales.

2) Por otro lado, e intercalando cierto trabajo intertextual con los Sesenheimer Gedichte, así como con pasajes de Werther, La nueva Melusina o El vicario de Wakefield de Oliver Goldsmith, releeremos también estos capítulos del romance alsaciano como escenario idealizado de lo femenino ${ }^{6}$. Acentuando la asimetría de su relación, el tratamiento del imaginario idílico y pastoril, o incluso pensando los ámbitos de la topografía, el baile, la música o el cuento, nos preguntaremos alternativamente si la figura de Friederike puede ser reevaluada desde otros campos proyectivos y desde qué estrategias de lectura.

\footnotetext{
J. Lacan, El mito individual del neurótico, o Poesía y verdad en la neurosis, Buenos Aires, Paidós, 2009.

Traduciremos este texto a partir de la "Weimarer-Ausgabe" (WA), en Goethes Werke. Herausgegeben im Auftrage der Großherzogin Sophie von Sachsen, vol 42.2: Literatur. Aus dem Nachlaß. Maximen und Reflexionen über Literatur und Ethik. Maximen und Reflexionen über Kunst, Natur und Wissenschaft. Vorarbeiten und Bruchstücke, Weimar, Hermann Böhlhaus Nachfolger, 1907, pp. 56 y ss.

6 Sobre este enfoque intertextual aplicado a los libros X y XI de Poesía y verdad quisiera señalar mi deuda con los trabajos de E. Bracht, "Wakefield in Sesenheim. Zur Interpretation des zehnten und elften Buches von Goethes Aus meinem Leben. Dichtung und Wahrheit", en Euphorion 83, 1989, pp. 261-280; H. Meller, "Literatur im Leben: Goethes Pfarrhaus in Sesenheim und Goldsmiths Landpfarrer von Wakefield", en Deutsche Vierteljahresschrift für Literatur und Geistesgeschichte 68, 1994, pp. 197-230; V. Hösle, "Erste und dritte Person bei Burchel und Goethe: Theorie und Performanz im zehnten Buch von Dichtung und Wahrheit", en Goethe-Jahrbuch 123, 2006, pp. 115-134; y R. Walter, "«Aus dieser fingierten Welt in eine ähnliche wirkliche versetzt»?: Die Theorie der Autobiographie und ein postmoderner Goethe”, en Goethe Yearbook 19, 2012, pp. 231-260.
} 


\section{Lacan en Estrasburgo.}

Empezaré por tanto con un détour de la mano de Jacques Lacan, que nos llevará indirectamente al corazón literario de Sesenheim. Como es sabido, "Le mythe individuel du névrosé, ou Poésie et vérité dans la névrose"7 es una conferencia pronunciada en 1953 en el Collège philosophique -aunque publicada en 1978-, en la que el psicoanalista francés realiza un comentario interpretativo de "A propósito de un caso de neurosis obsesiva" de 1909, esto es, el "Caso del Hombre de las Ratas" plasmado en la célebre nosografía freudiana ${ }^{8}$. Apoyándose en la comprensión estructuralista del mito de Lévi-Strauss, así como en su modelo de formalización de análisis etnográficos, Lacan dialoga aquí con el tópico freudiano del hombre neurótico que construye obsesivamente su propio mito individual. Su intención era mostrar cómo del relato y la constelación familiar de aquel paciente, descritos por Freud con una precisión casi novelesca, se podía obtener una definición del mito como estructura simbólica que otorga una fórmula discursiva a ese algo que no puede transmitirse como verdad, sino como una "cierta representación objetivada de un epos o de una gesta que expresa de manera imaginaria las relaciones fundamentales características de cierto modo de ser del ser humano en una época determinada" . Con ello, la verdad sólo podía ser expresada de un modo mítico, en el intersticio entre fantasma y escritura poética, recayendo su constitución sobre el uso progresivo de la palabra y el trazado de una constelación original dramática.

Sin embargo, lo realmente decisivo para nosotros empieza a mitad de conferencia, cuando Lacan decide ejemplificar esta teorización explorando el pasaje literario que activaba a Ernest Lers, el llamado "Hombre de las Ratas", a su intimidad masturbatoria ${ }^{10}$. Se trataba nada menos que del episodio de Poesía y verdad en el que el joven Goethe lograba superar, gracias a su noviazgo con Friederike Brion, una maldición amorosa -la prohibición de no volver a besar en los labios- lanzada contra él por la hija de su profesor de baile estrasburgués, la bella Lucinda. Toda aquella tensión, de fuertes connotaciones sexuales para Lers, marcaba la estrategia narrativa del romance alsaciano y las diferentes estructuras temporales en juego, desde su intuición poética antes de conocerla hasta el momento mismo de abandonarla ${ }^{11}$. Citamos por la excelente traducción de Rosa Sala:

Desde que aquella apasionada muchacha maldijera y santificara mis labios (pues toda consagración implica simultáneamente ambas cosas), me había guardado supersticiosamente de besar a ninguna muchacha, pues temía dañarla espiritualmente de una manera que no tenía antecedentes. Por ese motivo dominé la lascivia por

\footnotetext{
J. Lacan, op. cit., pp. 13-52.

8 S. Freud, A propósito de un caso de neurosis obsesiva (1909), en Obras completas, vol. X, Buenos Aires, Amorrortu editores, 1989, pp. 119-194.

J. Lacan, op. cit., p. 18.

10 S. Freud, op. cit., p. 160.

11 Como es habitual en su escritura, la escenificación de aquel conjuro sirve a Goethe para proyectar la anticipación intuitiva de un deseo inminente, un despertar intuitivo de sugerentes connotaciones pietistas. Otro pasaje inicial del libro X repetirá exactamente esta misma fórmula anticipadora, a saber, como un anhelo todavía desconocido que, buscado en la amplitud del territorio alsaciano, será contemplado en una "elevada y ancha plataforma de la catedral" de Estrasburgo, como un espectador de segundo grado cuya futura vida amorosa es objetivada en la sustancia misma de la visión (J. W. Goethe, Poesía y verdad, op. cit., p. 427).
} 
la que todo joven se siente impelido a ganarse esta gracia más o menos simbólica por parte de alguna encantadora muchacha ${ }^{12}$.

Con el beso de Friederike, sin embargo, terminará disipándose por fin la sombra de ese conjuro, liberándose el principio de placer y disolviendo las estructuras de un tiempo literario desde las que el yo autobiográfico había proyectado anticipaciones y expectativas de deseos futuros coartados por la violenta prohibición. El poeta así lo reconoce, en un desahogo franco y no exento de erotismo: "Todas mis manías hipocondríacas y supersticiosas habían desaparecido y, cuando se me ofreció la posibilidad de besar sinceramente a la que con tanta ternura amaba, no desaproveché y, desde luego, tampoco renuncié a repetir este placer"13.

A la vista de su posterior abandono y las enormes reticencias para expresar abiertamente su innegable culpa, tiene razón Lacan cuando caracteriza todo el idilio alsaciano como "uno de los episodios más enigmáticos de la vida de Goethe"14. No en vano ha sido uno de los pasajes más suculentos de su autobiografía para el psicoanálisis de corte freudiano, tal como había demostrado ya Theodor Reik en su monografía ¿Por qué abandonó Goethe a Friederike ${ }^{15}$, o, algunas décadas después, la investigación de Kurt Eissler ${ }^{16}$. Por otro lado, si atendemos a la alteración profunda que un maremoto como el Sturm und Drang tuvo en la vida de aquel talentoso aprendiz de poeta, quizá obtengamos una imagen mejor contextualizada de esa teoría de la juventud que el viejo Goethe nos ha legado para comprender aquella época de sentimentalismo ilimitado, entrega a la libertad y al goce de vivir.

Desde su llegada como doctorando a Estrasburgo, huyendo de una crisis personal en Leipzig y una crisis espiritual tras su fugaz experiencia pietista con los Hermanos Moravos, la renovada salud del estudiante de Derecho había encontrado en la movilidad social y cultural de la topografía alsaciana un irrepetible banco de pruebas para explorar, no las aburridas pandectas para su disputatio, sino el sentimiento emergente de una vocación literaria desde los parámetros no religiosos de una nueva individualidad. Como recuerda Boyle en su ya clásica biografía ${ }^{17}$, las comunidades pietistas en Estrasburgo, los "tan aburridos de corazón"18, garantizaron su desinterés por los problemas religiosos en favor de la intensidad emocional de la literatura, de un "yo" sacudido por las dimensiones de la fantasía, la creatividad y el genio. Impulsado por el magisterio teórico de la Abhandlung über den Ursprung der Sprache de Herder - convaleciente en aquella irrepetible buhardilla del "Auberge au grand Louvre"-, fue ese el arranque de su idilio moderno, a saber: en forma de excursiones por el bello territorio alsaciano, a la búsqueda osiánica de canciones populares y baladas perdidas, allí donde la inmediatez de la naturaleza, el idioma alemán y las

\section{Ibidem, p. 468}

13 Ibidem, p. 470. Por otro lado, esta fijación simbólica por el beso y los labios tiene su gran precedente literario en la violencia con la que Werther vive la prohibición de besar a Lotte, tal como reconstruyó Scott Abbot, "The Semiotics of Young Werther", en Goethe Yearbook 6, 1992, pp. 41-65, esp. p. 55 ss.

14 J. Lacan, op. cit., p. 39.

15 Th. Reik, Warum verließ Goethe Friederike? Eine psychoanalytische Monographie, Viena, Internationaler Psychoanalytischer Verlag, 1930.

16 K. Robert Eissler, Goethe: A Psychoanalytic Study 1775-1786, vol. 2, Detroit, Wayne State University Press, 1963, esp. pp. 1060-1070.

17 N. Boyle, Goethe. Der Dichter in seiner Zeit, vol. 1, Múnich, C.H. Beck, 1995, p. 117 ss.

18 Cf. la carta a Susanne von Klettenberg del 26 de agosto de 1770, en J. W. Goethe, Briefe ["Hamburger Ausgabe" = HA], K. Robert Mandelkow y B. Morawe (eds.), 4 vols., Múnich, Dtv, 1988, vol. I, p. 115. 
costumbres regionales confluyeron en retratos epistolares que sin duda anticipan el listón estético del romanticismo ${ }^{19}$.

Teniendo en cuenta este contexto esbozado, resulta interesante que numerosos detalles de la representación literaria del cortejo, noviazgo y abandono de Friederike impliquen para Lacan una "estructura verdaderamente tortuosa" ${ }^{20}$. No es sólo la latencia del temor, del miedo a la culpa futura, que ora blanquea con sus habituales máximas ${ }^{21}$, ora parece reconocer sin ambages, entremezclándola en sus símiles y alegorías ${ }^{22}$. Para Lacan y su forma de indagar este texto autobiográfico significa algo más. Es la riqueza de una construcción literaria que, transgrediendo contenidos y prácticas de la emocionalidad pietista, coquetea con un orden simbólico del patriarcado en el que el principio del placer y la normatividad social parecen confluir en una extraña sensualidad de rasgos neuróticos. Resulta sugerente, por ejemplo, la mirada del psicoanalista sobre la obsesión goetheana por el disfraz y la máscara para darse a conocer de incógnito entre la familia Brion, primero como desarrapado estudiante de teología, y luego, tras conocer a Friederike, como mozo de cuadra, maquillado y portando una torta de bautismo. “¿Es usted, joven señor? - preguntará la madre- ¿Cuántas apariencias tiene? En serio sólo una -repuse-, pero en broma todas las que quiera" 23 . Frente a la hospitalidad parroquial y la idílica representación arcádica del imago protestante (vicario rural y pater familias, madre y esposa honrada, hijas sencillas y humildes), emergen los trazos de un sainete identitario que, para Lacan, "está estrechamente ligado al juego sexual, al cortejo" ${ }^{24}$. De acuerdo con su mirada, el desdoblamiento de la propia función personal del sujeto en relación con él mismo remitiría a la "superficie de la corriente infinitamente más profunda que es la de la huida ante el objeto deseado"25. De ahí que el beso anhelado acabe acelerando la desdicha del sujeto deseante:

Pero ahora todo se había perdido y era irrecuperable. No sólo había regresado a mi vulgar estado anterior, sino que creía haber dañado al ser más encantador perjudi-

19 Cf. la deliciosa carta a Katharina Fabricius del 27 de junio de 1770, en HA I, pp. 109 y ss.

20 J. Lacan, op. cit., p. 41.

21 "No se me ocurrió pensar que quizá mi llegada habría venido a perturbar precisamente ese sosiego, pues una pasión que nace tiene el encanto de que, al ser inconsciente de su origen, no piensa tampoco en su final y, como se siente alegre y feliz, no intuye que también podría causar algún daño" (J. W. Goethe, Poesía y verdad, op. cit., p. 454).

22 "Mi apasionada relación con Friederike empezaba a atemorizarme. Semejante amor juvenil, mantenido así, sin más, se puede comparar a una bomba lanzada de noche, que sube al cielo en una línea suave y resplandeciente, se mezcla con las estrellas, incluso parece permanecer un instante entre ellas, pero después desciende trazando de nuevo la misma línea, aunque esta va en sentido contrario, para finalmente llevar la destrucción al lugar en que su recorrido se agota. Friederike no cambiaba nunca. No parecía pensar, ni quería hacerlo, en que esta relación podría terminarse pronto" (ibidem, pp. 511 y ss.).

23 Ibidem, p. 454

24 J. Lacan, op. cit., p. 43. Por otro lado, las explicaciones que aporta Goethe, a saber, que los dioses se disfrazaban para descender entre los hombres -temiendo perder su inmortalidad al no ir convenientemente enmascarados-, son teorizadas por Lacan desde la no asunción de cierta función sustitutiva paterna, en la medida en que no habría asumido tampoco su propia condición mortal. Eugenio Trías, al comentar este pasaje en su Prefacio a Goethe (Barcelona, Acantilado, 2006, p. 62), conecta este aspecto a la "actitud de Goethe respecto a la muerte, respecto a cuanto le sugiera negatividad; la clave para entender su curioso vitalismo antiheroico, salpicado de huidas y deserciones". Aunque en otro contexto de su obra, este miedo a la herida lo he desarrollado en una aproximación sobre Goethe y la guerra, cf. K. Lavernia, "Por ejemplo, Goethe en la guerra. Antropología de la experiencia histórica en Campagne in Frankreich", en J. B. Llinares (ed.), Antropología filosófica y literatura, Valencia, Pre-Textos, 2019 [en prensa].

25 J. Lacan, op. cit., p. 45. 
cándolo irremisiblemente. Y así, aquella maldición, en lugar de haberme deshecho al fin de ella, se había limitado a abandonar mis labios para devolverle el golpe a mi propio corazón ${ }^{26}$.

De nada sirve, concluye Lacan, que esta fórmula del fantasma en el neurótico explore otras vías de fuga, por ejemplo, a través de "la muy conocida historia del Vicario de Wakefield, transposición literaria, fantasmática, de su aventura" ${ }^{27}$. En efecto, todo el relato de Sesenheim, desde los personajes involucrados hasta la mise-en-scène rural, desde la temática idílica y la constelación familiar hasta el uso preferente de la ironía y el juego de máscaras, está construido a imagen y semejanza de la novela del escritor irlandés Oliver Goldsmith, publicada en 1766 e introducida por Herder entre los círculos estrasburgueses. A caballo entre una sátira didáctica de la novela sentimental y una memoria ficticia relatada por el vicario, Dr. Charles Primrose, la novela goldsmithiana, "una de las mejores que se hayan escrito nunca" 28 , había mostrado a Goethe un abanico de personajes arquetípicos, tramas amorosas y topografías ficcionales de la presunta vida moral rural que permitían transfigurar, a modo de espejo literario, su idilio alsaciano y generar así su propio mundo poético. Cierto, el narrador reitera a sus lectores que "mi inexplicable sorpresa se debía a verme rodeado en carne y hueso por la familia de Wakefield", pero en el fondo no late sino el deseo de llevar una vida según la literatura, un creativo deseo de sustitución y desdoblamiento que a veces puede resultar más significativo que la vida misma ${ }^{29}$.

En todo caso debemos terminar de pensar esta pista sugerida por Lacan. A fin de cuentas, revela una extraña intertextualidad de la que el picaresco narrador hace copartícipes a toda la familia alsaciana. Por ejemplo, les cambia el nombre por los equivalentes de la obra goldsmithiana ${ }^{30}$, confunde a los personajes ${ }^{31}$, o les lee incluso la obra, mostrándoles el irónico espejo que sustituye los objetos: "Aquí pudieron verse a sí mismos reflejados en un espejo que de ningún modo los afeaba. Si bien nadie lo reconoció abiertamente, nadie negó tampoco que nos estábamos moviendo entre personajes afines a nosotros en espíritu y sentimiento"32. Por otro lado, la exquisitez de esta escena de lectura, donde la literatura es vivida en la propia literatura, no debe llamarnos a engaño respecto de la asimetría del reflejo generado y la ambigüedad de tales identidades surrogadas. Tras numerosos vaivenes más propios del

26 J. W. Goethe, Poesia y verdad, op. cit., p. 474.

27 J. Lacan, op. cit., p. 46.

28 J. W. Goethe, Poesía y verdad, op. cit., p. 440.

29 Ibidem, p. 447. Como recuerda J. L. Villacañas ("Freud sobre Fausto: sustituciones de la omnipotencia", en Arbor. Ciencia, pensamiento y cultura CLXXXIII, 723, 2007, pp. 123-133, aquí p. 125), es este un rasgo decisivo de la Bildung clasicista señalado por Freud, consistente "en analizar la propia vida a partir de los personajes de la literatura", esto es, configurar un ethos adecuado al camino formativo "a la luz de los modelos literarios en circulación". Que el arte no imita la vida, sino que es la propia autobiografía la que imita el arte, es algo que, por lo demás, Goethe nos confirma cuando reconoce que "probablemente entre los intentos más excusables de atribuirse una dimensión más elevada, de equipararse a alguien superior, cuenta el afán juvenil de compararse con personajes novelescos" (J. W. Goethe, Poesía y verdad, op. cit., p. 476).

30 Ibidem, p. 447, 457, 481 ss.

31 Por eso Lacan insiste en que Friederike tiene un doble, la hermana Sophie, bautizada curiosamente como la Olivia del Vicario de Wakefield, cuya presencia confunde el recuerdo del neurótico. Cada vez que logra coincidir consigo mismo, su partenaire sexual se desdobla; cuando su vida amorosa se unifica, entonces aparece un doble narcisista que vive por procuración en su lugar (J. Lacan, op. cit., p. 46).

32 Ibidem, p. 476. 
género del slapstick, la satírica novela de Goldsmith terminaba en feliz matrimonio entre Sophie y el squire Burchell, restaurándose el orden moral dentro de la familia Primrose, mientras que, por el contrario, el galán squire Goethe no restauró orden alguno ${ }^{33}$. El recuerdo del neurótico adquiere las cotas de un juego amatorio harto ambiguo: el mito individual que este construye con ayuda de elementos de su pasado y de otro texto literario genera aquí una trama que produce un extraño efecto reflexivo sobre los propios entramados que sirve, no a la verdad del inminente abandono del galán, sino a la verosimilitud del momento poético:

Para la situación de los amantes en aquella bella orilla del Rin esta comparación a la que los había inducido una broma tuvo consecuencias de lo más agradable. Uno no reflexiona sobre sí mismo al contemplarse en un espejo, sino que se siente y se acepta. Así sucede también con esta clase de reflejos éticos en los que uno reconoce como en su propia sombra sus mismos hábitos y particularidades y trata de abarcarlas y abrazarlos con cariño fraternal ${ }^{34}$.

\section{El deseo reflejado, o sobre la dimensión entóptica.}

A la vista del frágil estatuto hermenéutico de Friederike, tal como Goethe lo codificó literariamente en su autobiografía, conviene ahondar un poco más en este vínculo entre el espejo y esta figura femenina, aparentemente menor, de su opus. Pero dejaremos a un lado la perspectiva psicoanalítica sobre el texto literario impresa por Lacan, cuyo interlocutor es a fin de cuentas Freud, alguien que por lo demás ya supo poner de relieve la capacidad hermenéutica de la literatura universal, en especial la del clasicismo goetheano. Al alejarnos de este détour, en el que se han sugerido algunas pistas sobre la particular organización nosográfica del caso Goethe y el desgarramiento del "yo" entre vida y escritura de sí, entre la voluntad de goce de la fantasía y las coacciones del principio de realidad, las vivencias representadas en este recuerdo amoroso invitan a plantear la pregunta de si Friederike es algo más que la construcción retrospectiva de un objeto deseado por un joven de rasgos neuróticos. Es preciso, pues, indagar no tanto por la verdad mítica lacaniana que emerge entre escritura y fantasma, sino más bien por el tipo de experiencia de verdad, de "verdad esencial", que para el viejo Goethe se jugó en semejante autoestilización literaria. Por verdad esencial (das eigentliche Grundwahre) entenderemos la verdad que se oculta detrás de los hechos, dándose a significar simbólicamente a través de la poetización del recuerdo de sí mismo en su rodeo (per)formativo por el mundo. Al fin y al cabo, para el hombre de acción goetheano lo importante no es la sucesión real de acontecimientos vividos, sino "la verdad esencial que, en la medida en que yo podía reconocerla, había imperado en mi vida" ${ }^{35}$. Es el mecanismo último de orientación

33 Antes bien, desde los parámetros socioculturales de una vicaría rural de mediados del siglo XVIII, Goethe sembró el caos y dejó ante todo un corazón roto. Es muy probable que Friederike nunca terminara de superar su amor por Goethe, además de quedar socialmente estigmatizada por el fallido cortejo. Quedó soltera toda su vida, viviendo de un pequeño comercio de tejidos, de sus labores femeninas y de tomar niñas en pensión. Murió en 1813 .

34 Ibidem, p. $476 \mathrm{~s}$.

35 Cf. la carta al rey Luis I de Baviera del 17 de diciembre de 1829, en HA IV, p. 363. Cf. también la conversación con Eckermann del 30 de marzo de 1831, en J. W. Goethe, Conversaciones con Eckermann, Barcelona, Acanti- 
del "yo" autobiográfico, la instancia que reduce lo múltiple a un sentido que permite avanzar por su vida a ese "yo" como movimiento abierto del poetizar mismo.

A este respecto, sería reduccionista centrarse sólo en las huellas goetheanas de su organización pulsional básica, apostarlo todo a la convicción psicoanalítica de que las figuras literarias dan expresión a fuerzas subjetivas y pasiones que operan en cada individuo. Aunque el equilibrio nunca resulte fácil, la condición de verse siempre perseguido por sus orígenes, o por las sombras inalcanzables de un síntoma, debe ser mesurada tanto en sus virtudes como en sus limitaciones. Cierto, de la autobiografía puede decirse que ocupa un lugar entre la pérdida y el encuentro, un espacio liminal donde lo extraviado sólo puede ser recordado, y lo que puede ser posible, únicamente anticipado. Sin embargo, la ventaja crucial de la escritura de madurez goetheana radica en que nos ofrece un saludable e irónico ejercicio de resistencia existencial, a saber: como una hermenéutica de sí proyectada sobre el dominio de sus propias creaciones literarias, en la que nos muestra la necesidad de dejarse temporalizar, a fin de seguir reconociéndose en el presente. Como recordó Reinhart Koselleck en su homenaje al poeta ${ }^{36}$, alguien que en su vejez inició una relación histórica consigo mismo, que se percibió como un objeto historiable, mientras que, al mismo tiempo y estando todavía vivo, se iba convirtiendo en un monumento del espacio cultural alemán, sabía que todo intento por controlar su propia historia como historia efectual e indagar sobre ella chocaba con el destino impredecible de toda refracción temporal de la experiencia. Con un olfato innegable, el teórico de la historia insistió en que Goethe

deseaba sacar a la luz las influencias del exterior que desde el pasado o el presente habían posibilitado sus obras. Y asimismo tenía en cuenta, a través de muchos canales intermediarios, el efecto de su propia obra. Con esta doble eficacia histórica logró dar la vuelta al género de las memorias y superar la tradicional alternativa entre reflejar lo subjetivo u observar lo objetivo ${ }^{37}$.

En este sentido, que la construcción literaria realizada en su autobiografía de juventud había alterado la comprensión de la experiencia amorosa vivida en la vicaría alsaciana, es algo a lo que Goethe tuvo que hacer frente precisamente en sus últimos años de vida, máxime cuando los concernidos libros de Poesía y verdad tuvieron un enorme éxito entre el público de la época. Haber borrado u ocultado casi todas las huellas de cara a su autoestilización de madurez no era, desde luego, suficiente para impedir ese momento inherente a toda recepción de un texto literario ${ }^{38}$. Transcurri-

lado, 2005, p. 563 .

36 R. Koselleck, "La historia intempestiva de Goethe", en Atlantis. Revista de pensamiento y educación 3, 2014, pp. 69-88, aquí p. 76.

37 Ibidem.

38 En efecto se "perdieron" la treintena de cartas que se intercambiaron Goethe y Friederike. De este romance sólo conservamos como fuentes directas dos esbozos epistolares con fecha de octubre de 1770 (en HA I, p. 117), así como cinco cartas dirigidas a su mejor amigo de entonces, J. D. Salzmann (en WA IV, 1, pp. 258-263), publicadas por cierto en contra de la voluntad de un Goethe preocupado por la reacción del público (cf. la carta a Ch. M. Engelhardt del 3 de febrero de 1826, en WA IV, 40, p. 285; para más detalles Meller, "Literatur im Leben", op. cit., p. 200 s.). En estas epístolas, el doctorando proyecta abiertamente su culpa y sus remordimientos de conciencia, a la manera de un Eneas que, aun a sabiendas de que abandonará a Dido, hará que se enamore de él (Virgilio, Eneida, I, 603). Las cartas revelan fuertes oscilaciones en los sentimientos del enamorado. Por de pronto se compara con una "veleta", que se mueve según la dirección del viento. El mundo es para él "tan bello 
dos más de cincuenta años, la imagen de Friederike se había transformado, cuando menos, en un doble sentido que el poeta ya no podía controlar a través del mero trabajo en el mito de sí mismo.

Por un lado, debemos recordar que el ciclo poético conocido como las Canciones de Sesenheim (Sesenheimer Lieder), algunas de las cuales se habían publicado ya en 1775 en la revista Iris de Jacobi, se había asentado ya, como tantas de las producciones líricas goetheanas, en el imaginario colectivo de un espacio cultural que empezaba a historizar el período del Sturm und Drang y a seleccionar por tanto sus lugares de memoria ${ }^{39}$. En aquellos versos juveniles, inspirados en el romance con Friederike Brion, Goethe se asomaba al mundo sencillamente como lírico, liberado del rococó y del anacreontismo de los años de Leipzig, al tiempo que materializaba en ellos el influjo teórico de Herder, a saber: naturalidad, fuerza de expresión subjetiva, gusto despreocupado en las modalidades de expresión, reflexividad sin palidez de pensamientos, sencillez y simbolismo sin artificiosidad. Desde esta perspectiva, las Canciones de Sesenheim suponen innegablemente un punto de inflexión en la historia de la lírica alemana, y su ocasión, su Gelegenheit, el pueblo de poetas y pensadores se la debía a la hija del pastor, a quien se la condenaba, sin embargo, a mantenerse joven y adorable, pasiva e instrumental, eternamente objeto de la palabra poética. Para mayor deleite del emergente público burgués, aquellos poemas ("Mayfest", "Willkommen und Abschied", "Kleine Blumen, kleine Blätter") habían sido entrelazados con los versos de amor de Lenz, alguien cuya desgraciada vida sentimental también estuvo ligada a Friederike en 1772 y 1773.

Por otro lado, la imagen de Friederike empezaba a trascender también el espacio poético en favor de las transformaciones literarias de cuño romántico, visibles ya, por ejemplo, en la novella de 1822 publicada por Ludwig Tieck "Der Mondsüchtige" ("El Lunático"), el primero que inauguró las peregrinaciones a la vicaría alsaciana ${ }^{40}$. Ese gesto anticipaba las futuras controversias filológicas y biográficas de la llamada Friederikenliteratur, un subgénero propio del espíritu Biedermaier que a lo largo del siglo XIX generaría numerosas adaptaciones teatrales y novelísticas, parodias, merchandising kitsch y discusiones microscopistas ${ }^{41}$. Y Goethe lo llegó a vivir en primera persona, al recibir el envío de un ensayo titulado "Peregrinación a Sesenheim", escrito por un filólogo de Bonn llamado August Ferdinand Näke ${ }^{42}$, cuya visita a la vicaría, a los lugares reales del romance, a los personajes todavía vivos, le había impactado sobremanera, al verse literalmente transportado al espíritu del texto de Poesía y verdad. El viejo poeta aprovechó entonces la ocasión para rendir cuentas con aquellos sentimientos proyectados con ayuda de elementos de su pasado y reflexionar sobre la transformación de la experiencia en arte, como una gradación de

como no me lo parecía desde hace mucho tiempo". Pero luego se produce un súbito cambio. Siente "que no se tiene un ápice más de felicidad cuando se consigue lo deseado".

39 Basta con pensar, por ejemplo, en la temprana adaptación a Lied por parte de Schubert, en 1822, del poema "Bienvenida y adiós", cuyas dos primeras estrofas son más que conocidas: "Es schlug mein Herz, geschwind, zu Pferde! / Und fort, wild wie ein Held zur Schlacht”. Sobre los Sesenheimer Lieder continúa siendo útil el trabajo introductorio de H. Brandt, "Goethes Sesenheimer Gedichte als lyrischer Neubeginn", en Goethe-Jahrbuch 108, 1991, pp. 31-46.

40 L. Tieck, Schriften, vol. V, Berlín, Reimer, 1853, pp. 115 y ss.

41 Sobre este tema, cf. H. Stipa Madland, "Poetic Transformations and Nineteenth-Century Scholarship: The 'Friederikenliteratur", en Goethe Yearbook 8, 1996, pp. 28-44.

42 Este ensayo será publicado tras la muerte del poeta; cf. A. F. Näke, Wallfahrt nach Sesenheim, K.A. Varnhagen von Emse (ed.), Berlín, Duncker \& Humblot, 1840. 
nueve etapas que muestra cómo de manera indefectible la literatura acaba superando siempre la realidad. Redactado en 1823 para responder en agradecimiento a Näke, este decálogo del recuerdo amoroso sobre Friederike Brion esconde una extraña riqueza filosófica que restaura la dignidad hermenéutica de Friederike y merece por tanto transcribirse en su integridad:

Para expresar mi opinión sobre las recientes noticias de Sesenheim, tengo que emplear un símbolo, en general de tipo físico, pero en particular tomado de la entóptica; se tratará aquí sobre reflejos repetidos.

1) Una feliz desilusión [Wahnleben] juvenil se refleja de manera inconsciente e impactante en el joven.

2) La imagen largamente perseguida, y probablemente también renovada, va ondeando en su interior, amena y graciosa, durante muchos años.

3) Lo tiernamente obtenido en años tempranos, por largo tiempo retenido, es expresado finalmente hacia afuera, como un vivo recuerdo, y es reflejado de nuevo.

4) Esta imagen posterior se irradia en todas direcciones por el mundo, y un alma bella y noble puede deleitarse con esta aparición [Erscheinung] como si fuese realidad, recibiendo de ella una profunda impresión.

5) De aquí en adelante se despliega un impulso a realizar todo aquello que todavía pueda ser conjurado desde el pasado.

6) El anhelo crece y, para saciarlo, se vuelve irremediablemente necesario volver al lugar para apropiarse, cuando menos, del paraje.

7) Aquí se da la feliz coincidencia de que en el lugar conmemorado se encuentra a un hombre partícipe e instruido en el que la imagen se ha impreso igualmente.

8) Aquí, en la localidad por así decirlo desolada, surge la posibilidad de restaurar de nuevo un algo verdadero, procurarse una segunda presencia de las ruinas de la existencia y de la tradición, y de amar a la Friederike de tiempos pasados en toda su amabilidad.

9) Ahora, a pesar de toda esta intervención terrenal, ella puede ser nuevamente reflejada en el alma del viejo amante, reavivando en él una presencia dulce, valiosa y vivificante.

Pues bien, si tenemos en cuenta que los repetidos reflejos morales no sólo mantienen vivo el pasado, sino que incluso lo elevan a una forma de vida superior, entonces uno se acuerda de los fenómenos entópticos que, del mismo modo, no palidecen entre espejo y espejo, sino que se enardecen tanto más. Entonces obtendremos un símbolo de aquello que con frecuencia se repite en la historia de las artes y las ciencias, de la iglesia e incluso en el mundo político, y que continúa repitiéndose a diario ${ }^{43}$.

Sin duda es bella la analogía, deudora de sus estudios posteriores a la Teoría de los colores de 1810, y más específicamente del descubrimiento malusiano de la polarización de la luz por la reflexión y su doble refracción en cristales ${ }^{44}$. Es una trasposición

J3. W. Goethe, "Wiederholte Spiegelungen", en WA I, 42.2, pp. 56 y ss.

44 J. W. Goethe, Sämtliche Werke nach Epochen seines Schaffens ["Münchner Ausgabe" = MA], vol. 12: Zur Naturwissenschaft überhaupt, besonders zur Morphologie. Erfahrung, Betrachtung, Folgerung, durch Leb- 
típicamente goetheana, en ese puente aparentemente infranqueable entre las ciencias naturales y el ámbito de lo poético. Así como los fenómenos entópticos podían ser explicados en términos de percepciones o más bien perturbaciones visuales, cuya fuente eran los ojos mismos, en las que mediante la refracción prismática se observaba experimentalmente no sólo el reflejo de un objeto, sino su intensificación o Steigerung tras pasar por cada uno de los espejos, así también la impresión de las "imágenes posteriores" o Nachbilder de Friederike, es decir, los reflejos generados en virtud de la externalización y repetición de aquella imagen revivida del pasado, habían actuado en el presente de los lectores contemporáneos de Poesía y verdad. Podría aventurarse también la tesis de una suerte de poetología de los reflejos repetidos, un procedimiento compositivo desde cuya serialización, variación y contraste nace la defensa de una perspectivización y por tanto pluralización de los objetos poéticos en el tiempo, convirtiéndose en un principio clave de toda representación.

En cierto modo, pues, la imagen de aquella figura femenina adquiría, para el viejo consejero áulico weimarés, un estatuto simbólico propio en virtud del juego de espejos generado por la propia literatura. Era imposible volver románticamente al momento fundante y originario del locus amoenus de Sesenheim, sino que, antes bien, en la toma de conciencia de la refracción especular de las imágenes transmitidas radicaba el aprendizaje hermenéutico, el magisterio de la diferencia histórica en virtud de la experiencia literaria. No es que la imagen original de la hija del pastor hubiese sido solo recreada estéticamente, sino que, con cada instancia de repetición, la desilusión juvenil se había transformado en la propia dimensión entóptica de la vida refractada, de manera que lo presentificado y lo recordado parecían figurar en una misma realidad temporal que sobrepasaba los límites de la realidad presente, cuyos efectos parecen verdaderos porque son efectivos, que no reales: wirksam, no wirklich. Tal es el poder de la Vergegenwärtigung simbólica o segunda presencia, que, gracias al poder del lenguaje figurado, de su poner ante los ojos, nos salva "de las ruinas de la existencia y de la tradición".

\section{3. ¿Quién es Friederike? Algunos hilos de los que tirar.}

Si atendemos por tanto a las reflexiones del viejo escritor, la "verdad" de Friederike Brion, su dignidad literaria como figura femenina en la obra goetheana, parece residir sobre todo en el efecto transformador que su deleite supo generar entre los lectores contemporáneos de la autobiografía. El clasicismo de madurez de Goethe, que siempre se mantuvo fiel al prodesse aut delectare de la poética horaciana, nos muestra que la verdad esencial que se oculta detrás de los hechos vividos apunta a la efectividad retórica de una producción de significados que se despliegan a través de la repetición no idéntica de los símbolos de la vida humana. No hay sino un proceso iterativo de símbolos, que en el caso concreto de Friederike, tras más de cinco décadas transcurridas, asume la forma de la repetición de lo imposible, a saber: la repetición del deseo y la segunda presencia de la enamorada.

En la reflexión final del poeta alemán, la tipificación y estilización literarias de una figura como la hija del pastor nos sugiere que este no pretendió encadenarla ya

ensereignisse verbunden, Múnich, Carl Hanser, 1989, pp. 473-517. Por otro lado, Goethe también le dedicará a estos fenómenos un poema con el título "Entoptische Farben", dirigido a Julie von Egloffstein, en MA 11.1.1, p. 183. 
al mito de sí mismo, ni petrificarla por tanto, como sí pensaron los representantes decimonónicos de la Friederikenliteratur, como una bella mónada en el panteón atemporal y tópico de lo eternamente femenino ${ }^{45}$. Antes bien, el tardío juego de espejos de Sesenheim nos muestra cómo la segunda presencia de la amada en el alma del amante ha perdido sus rasgos platónicos: primero, porque aunque esta particular anamnesis revista ciertos rasgos dialógicos, ha surgido de la experiencia transformadora de la fragmentación de todo el entramado vital, de la construcción ruinosa de imágenes serializadas que es la existencia; y segundo, porque la reflexión distante del autor no desea una vivificación idealizada de Friederike, sino sobre todo captar el proceso de gestación literaria de su significatividad como construcción simbólica de imágenes repetidas, a fin de deleitarse también en ellas. En definitiva, pues, lo que se presentifica en aquel episodio con enorme autenticidad, la inmediatez e intimidad de la vida que ama, la bendición del desbordante instante amoroso y la verosimilitud de la entrega al amor (que sólo es posible en el presente), es la sustancia misma de la vida, pero paradójicamente su recreación sólo puede venir de la literatura y no remite a algo más allá de ella.

Armados con estas nuevas herramientas aportadas por el viejo Goethe, la relectura de los mentados libros de Poesía y verdad continúa siendo un gesto válido para refrendar la potencialidad de la figura de Friederike. Algunos campos proyectivos de su Sosein ya han sido sugeridos a lo largo de nuestra investigación, y aunque ciertamente estén idealizados, son imprescindibles para reevaluarla con otros ojos desde los parámetros arriba esbozados, así como con herramientas teóricas utilizadas por la Goetheforschung más reciente. Sin ánimo de exhaustividad, terminaremos con una invitación a seguir leyendo el lugar de Friederike a partir de los ámbitos ejemplares de la topografía, del baile, la música y el cuento.

Respecto del primer ámbito, en efecto, las tensiones topográficas entre Sesenheim y Estrasburgo acentúan los motivos idílicos, el imago patriarcal doméstico, la oscilación rousseauniana entre amor y amistad o la inevitable asimetría social de la relación. También los agradables rasgos físicos de Friederike y los de su sencilla personalidad $^{46}$, así como la meditada puesta en escena arcádica de su romance, juegan en todo momento con la dicotomía entre campo y ciudad, entre naturalidad originaria y artificialidad urbana. Es el poso teórico del Sturm und Drang antes aludido. Así, mientras que "los cordiales saludos que los campesinos le dirigían sobre todo a ella ya daban a entender que siempre se mostraba bondadosa y procuraba su bienestar" ${ }^{47}$, la visita a la ajetreada Estrasburgo por parte de la madre y las dos hermanas, "a las que sólo estaba acostumbrado a ver en un entorno campestre", acentúa la diferenciación social y por tanto los límites de la relación: "Ahora, por primera vez, las veía en el escenario de unas estancias urbanas que, aun siendo amplias, estrechaban su entorno y remitían a tapicerías, espejos, relojes de antesala y muñecas de porcelana"48. Tales contrastes, que anticipan la separación, se materializan asimismo en la diferente vestimenta (francesa en un caso, alemana en el otro), los gustos literarios

45 En este sentido, no sorprende que esta visión fuese la de un georgiano como Friedrich Gundolf, que en su famosa monografía llevó esta actitud hasta el paroxismo, afirmando que "la vida y la creación de Goethe son incomparablemente más importantes ante Dios y el mundo que mil Friederikes" (cf. F. Gundolf, Goethe, Berlín, G. Bondi, 1918, p. 144).

46 J. W. Goethe, Poesía y verdad, op. cit., p. 445 s., 469, 472.

$47 \quad$ Ibidem, p. 469.

$48 \quad$ Ibidem, p. 481. 
de uno y otro ${ }^{49}$, la escritura de sus $\operatorname{cartas}^{50}$, el cuerpo de su letra "ligera, bonita y franca" ${ }^{51}$. En todos estos casos, vemos confirmado cómo en el aprendizaje mutuo del amor y la semántica de la intimidad se juegan también la gradación ascendente de los significados establecidos firmemente en el código, y "es en ese código y mediante ese código - por decirlo con el clásico estudio de Luhmann- como pueden llegar a hacerse comprensibles las diferencias, destacando así la falta de plenitud" 52 .

Otro ámbito algo más complejo, pero íntimamente relacionado con la cuestión de la semántica del amor en el umbral de época del Sturm und Drang, es el tema del baile:

El deseo que sentía aquella sociedad por escuchar música se satisfizo al fin: la música se hizo oir y todo el mundo salió a bailar a toda prisa. Las alemandas, los valses y los giros fueron tanto el principio, el medio como el final del baile. Todos habían crecido educados en esta danza nacional. Tampoco yo dejé en mal lugar a mis secretas maestras de danza, y Friederike, que bailaba del mismo modo que caminaba, saltaba y corría, se alegró de tener en mí a una pareja de baile experta. Bailamos juntos la mayor parte del tiempo ${ }^{53}$.

El baile, como sabemos, es una decisiva codificación cultural del amor y la intimidad. En la medida en que aceptamos, siguiendo de nuevo a Luhmann, "que el «medio de comunicación» amor no es en sí mismo un sentimiento, sino un código de comunicación de acuerdo con cuyas reglas se expresan, se forman o se simulan

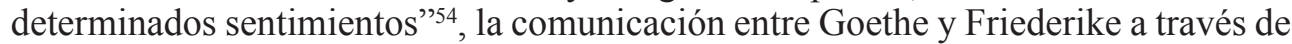
las diferentes formas de baile relatadas en Poesía y verdad funciona como una sutil graduación de distancias representadas donde se negocia, sin embargo, la cercanía de sus cuerpos. Mientras que las alemandas remiten, como danza popular barroca de compás cuaternario o binario, a un juego de brazos entrelazados generador de distancia, el acercamiento de los cuerpos en el vals, es decir, la íntima experiencia y expresión corporales de la pareja, escenifica la emergencia de un código simbólico de mayor complejidad, como el propio Goethe había mostrado de manera insuperable en el vals extático con Lotte de Las penas del joven Werther. En ese vals, en la primera noche que se conocen, no sólo se proyectaban los deseos eróticos de una subjetividad literaria excesiva, a ratos histérica y neurótica, sino que se ratificaba, sobre todo, la incapacidad wertheriana por lidiar internamente con la simplicidad de aquella figura femenina: "Ya no era un hombre" -llegó a decir Werther al bailar con Lotte-Ich war kein Mensch mehr ${ }^{55}$.

Así como los rasgos de la personalidad armónica de ambas figuras femeninas, Lotte y Friederike, convergen en la dimensión performativa del baile, también la

49 Amante del sencillo cancionero popular de Alsacia y Suiza, Friederike se ruboriza con la recitación goetheana del Hamlet y le resulta extraña esa melancolía shakesperiana (ibidem, pp. 482 y ss.).

50 Ibidem, p. 475.

51 Ibidem.

52 N. Luhmann, El amor como pasión. La codificación de la intimidad, Barcelona, Ediciones Península, 1985, p. 21.

53 J. W. Goethe, Poesía y verdad, op. cit., p. 472.

54 N. Luhmann, op. cit., p. 21.

55 Para mayores detalles en esta comparativa, remitimos al trabajo de L. Ruprecht, "Werthers Walzer...", op. cit., esp. pp. 45-49. 
dimensión de la música anudará los dos momentos literarios de Wahlheim y Sesenheim. Ambos personajes, en efecto, cantan y tocan el piano frente a sus espectadores enamorados; sus gestos y maneras, observados atentamente como un tableu $^{56}$. Y sin duda sería reduccionista explicar este paralelismo como mero vehículo estético para plasmar el conocido contraste herderiano entre el lenguaje directo y natural de una simple melodía frente a la artificialidad del lenguaje contemporáneo. Pero la importancia de la música visibiliza quizá otra derivada menos evidente de esta comprensión del ser humano como criatura y creador del lenguaje, a saber: cómo los sentimientos que habitan detrás de él son objeto de intercambio, exposición y negociación social. Tal es la función, primero, de las piezas musicales interpretadas por Friederike para el falso estudiante de teología, si bien por indicación expresa de la figura paterna ${ }^{57}$. A continuación, sin embargo, subrayando el carácter doméstico y rural del locus amoenus, la propia pianista recomienda salir a cielo abierto: "Salgamos afuera, que así podrán escuchar mis canciones suizas y alsacianas que ya suenan bastante mejor"'58.

Por último, la negociación de sus identidades no sólo se jugará en términos estrictamente musicales, sino que también se problematizará en la dimensión fantástica de la oralidad literaria, en este caso en forma de un cuento que, curiosamente, no sería publicado hasta 1817, incorporándose después a Los años de peregrinaje de Wilhelm Meister, de 1821. El narrador, que se espera a que el padre de Friederike se vaya "a dormir la siesta", sugiere en efecto que "fuimos a una amplia glorieta y yo les conté un cuento que adelante pondría por escrito bajo el título de La nueva Melusina" 59 . En la famosa versión de Goethe, la princesa Melusina se transforma en una enana que reside en el interior de una caja misteriosa que su frívolo amante debe custodiar. Al averiguar la transformación maravillosa de su amada y contravenir la prohibición, sólo le quedan dos opciones: perderla para siempre o disminuir de tamaño y acompañarla al reino de los enanos. Opta por lo segundo, pero cuando se da cuenta de que eso implica el matrimonio con ella, decide huir. Es significativo que también Friederike, como Melusina, sea abandonada en el momento en que la relación amorosa abandona la esfera de lo maravilloso para transformarse en un compromiso real. En el cuerpo escindido de Melusina se juega, anticipándose, la imposibilidad del compromiso goetheano, la escisión de sus dos mundos, no menos que el secreto codificado de las dudas y la culpa futura.

\section{Epílogo a modo de invitación}

La paradójica potencialidad del género autobiográfico, tal como se juega en Poesía $y$ verdad, radica en que resulta enriquecedor incluso cuando o precisamente porque difunde errores fácticos. Como confesará a Eckermann, "un factum de nuestra vida no tiene vigencia en la medida en que sea verdadero, sino en la medida en que tiene algo que significar" ${ }^{\circ}$. En este sentido, el episodio amoroso no ofrece sin más algunas

\footnotetext{
Sobre este punto, seguimos el trabajo de Abbot, "The Semiotics of Young Werther", op. cit., pp. 58 y ss.

J. W. Goethe, Poesia y verdad, op. cit., p. 446.

Ibidem.

Ibidem, p. 459. Para más detalles, cf. Walter, “Aus dieser fingierten Welt...”, op. cit., pp. 243-248.

Conversación del 31 de marzo de 1831, en J. W. Goethe, Conversaciones con Eckermann, op. cit., p. 564.
} 
claves sobre la éducation sentimentale de un joven poeta en el umbral de época del Sturm und Drang, sino que nos dice algo sobre la imagen de sí de un viejo autor que intenta hacer un balance de aquella semántica de la identidad que dio "un nuevo empuje a la individualización por encima de su simple presencia en el sentimiento" 61 . Mediante un determinado posicionamiento literario, de entrecruzamiento de géneros y juegos intertextuales, trata de hacer plausible el surgimiento de una precaria subjetividad con los propios medios narrativos de aquel umbral de época, escenificando la emergencia simbólica de su naciente condición como autor (enamorado), así como la necesidad existencial del propio proceso de escritura. Es decir: escenificar la precaria estructura descubierta del poetizar mismo, cuya representación sólo se genera en el propio representar. De ahí que los reflejos repetidos de la propia productividad literaria, como la propia figura de Friederike Brion, sean siempre "sólo" un testimonio del enigmático proceso de intercambio creativo entre vida y poesía, entre facta y ficta. Tal es la extraña relevancia de esta paradoja sobre la ficcionalidad de lo fáctico, a saber, que la verdad sobre los sentimientos expresados por un sujeto autobiográfico llamado "Goethe" sólo podrá ser producida en el propio texto como configuración narrativa, del mismo modo que la vida fáctica no es accesible de manera directa, sino siempre sólo como producto de estrategias narrativas y de un entramado (emplotment). Texto y vida jamás coincidirán en la figura amada de Friederike.

${ }^{61} \quad$ N. Luhmann, op. cit., p. 145. 